\title{
A complicated case of mitral valve disease
}

\author{
STEPHEN E JAMES, ^ ROXANE MCKAY,† DONALD N ROSS \\ From the Middlesex Hospital, London
}

SUMMARY A patient with rheumatic mitral stenosis and previous cerebral embolism had a myocardial infarction during cardiac catheterisation. She later developed severe mitral regurgitation one year after open valvotomy and at valve replacement was found to have a papillary tumour of the mitral valve. Unexplained low cardiac output occurred four days after operation. Postmortem examination showed thrombotic occlusion of the xenograft prosthesis, a complication not previously seen with tissue valves. Both of these rare events were suggested by the patient's clinical course and could have been diagnosed with cross sectional echocardiography.

Symptoms of mitral stenosis may be identical to those of left atrial myxoma, and both lesions may coexist, ${ }^{1}$ but the clinical importance of the more rare papillary tumour of the heart ${ }^{2}$ and its relation to these two conditions is less well defined. In the present report, a mitral valve papillary tumour (or giant Lamdl's excrescence) may have caused many complications attributed to the patient's rheumatic mitral stenosis. In addition, the early postoperative occlusion of a xenograft prosthesis is reported.

\section{Case report}

A 57 year old woman was referred for cardiac assessment in November 1979. She had had rheumatic fever at 18 years of age, and three pregnancies were complicated by heart failure. Subsequently, only mild dyspnoea occurred on effort, but in 1977 she had a left cerebral embolus while in sinus rhythm.

Physical examination showed signs of predominant mitral stenosis with mild mitral and aortic regurgitation as well as a residual right hemiparesis. An electrocardiogram confirmed sinus rhythm and left atrial enlargement, while chest $x$ ray films showed a dilated left atrium and upper lobe blood diversion. At cardiac catheterisation, there was a resting gradient of $10 \mathrm{~mm}$ $\mathrm{Hg}$ across the mitral valve and a pulmonary artery

Requests for reprints to Mr D N Ross, Middlesex Hospital, Mortimer Street, London W1N 8AA.

Present addresses: ${ }^{\star}$ Department of Orthopaedic Surgery, Princess Margaret Hospital, Swindon, Wiltshire; tThe Royal Liverpool Children's Hospital, Myrtle Street, Liverpool L7 7DG. pressure of 50/24 mm $\mathrm{Hg}$. Angiography detected slight mitral and aortic regurgitation, good left ventricular function, and normal coronary arteries. Several minutes after completion of the catheter study, the patient experienced chest pain and bradycardia. Changes of inferolateral ischaemia on the electrocardiogram evolved, and myocardial necrosis was confirmed by an increase in serum creatine phosphokinase activity from 74 to $1679 \mathrm{U} / \mathrm{l}$. Review of events at catheterisation suggested no obvious cause for the myocardial infarction.

Six months later an open mitral valvotomy was performed and the left atrial appendage amputated. The valve was mobile, without calcification, and remained competent after the commissures were opened to a diameter of $4.5 \mathrm{~cm}$. There was no clot in the left atrium, but the apex of the heart was thin and scarred, consistent with previous myocardial infarction. The patient's postoperative recovery was complicated by multiple episodes of ventricular tachycardia and fibrillation; but, eventually, she was discharged from hospital in sinus rhythm and without signs of heart failure.

The next 18 months saw gradual deterioration from progressive mitral and tricuspid regurgitation, which was made worse by the onset of atrial fibrillation. In addition to several admissions for ventricular and atrial arrhythmias, she required admission to hospital for pneumonia, pulmonary embolus, and eventually severe congestive heart failure. Reinvestigation in October 1981 showed moderate restenosis of the mitral valve, which was now severely regurgitant. The anterior leaflet appeared mobile on cross sectional 

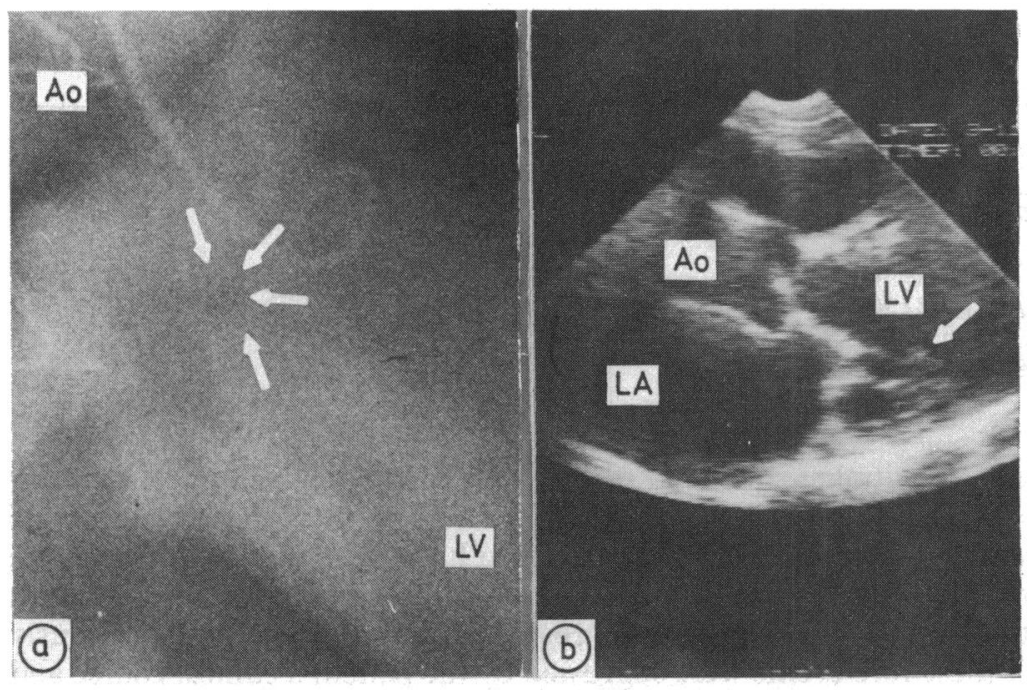

Fig. 1 (a) Lateral view of left ventricular angiogram and (b) long axis view of echocardiogram showing the mass attached to the mitral papillary muscle (arrows). Ao, aorta; LV, left ventricle; $L A$, left atrium.

echocardiography, but the posterior leaflet was rigid and the left atrium greatly enlarged (Fig. 1). Angiography showed anterior and apical akinesis of the left ventricle with abrupt occlusion of the posterior descending coronary artery. A thallium perfusion

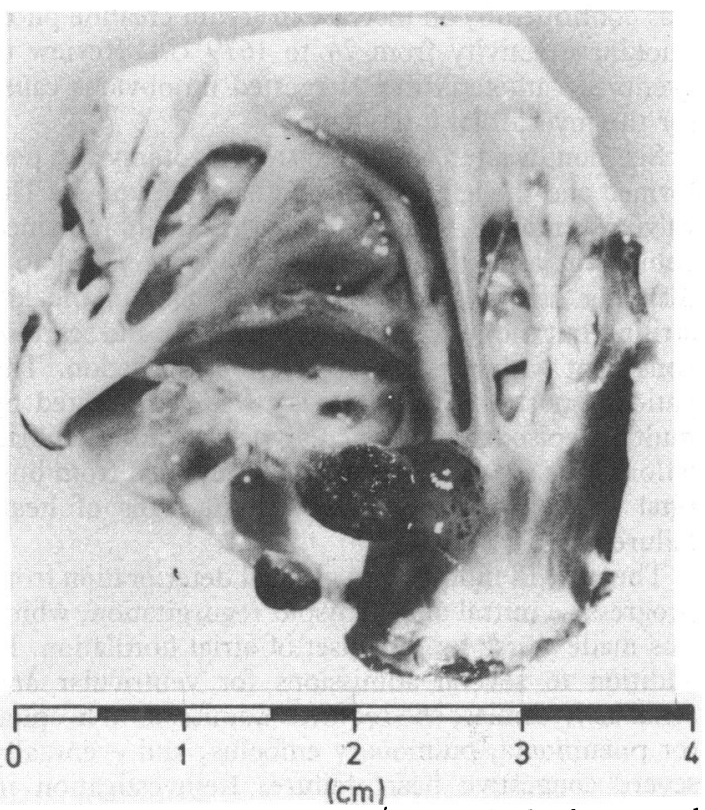

Fig. 2 Morphological appearance of the mitral valve removed at the second operation. The tumour mass is attached to the anterolateral papillary muscle. scan showed infarction of both the inferior wall and apex, consistent with involvement of two coronary arteries. A lung scan was now normal as were coagulation studies.

At a second open heart operation in March 1982, the mitral valve was replaced with a $25 \mathrm{~mm}$ Carpentier-Edwards xenograft using continuous $2 / 0$ monofilament suture reinforced with a strip of Teflon felt along the posterior mitral annulus. Tricuspid regurgitation was repaired by a modified De-Vega annuloplasty. In addition to thickening of the mitral valve leaflets, a papillomatous jelly-like mass was found on the anterolateral papillary muscle (Fig. 2). Severe low cardiac output in the immediate postoperative period responded to isoprenaline, dopamine. Intermittent mandatory ventilation had and by the third postoperative day satisfactory haemodynamics were maintained with $5 \mu \mathrm{g} / \mathrm{kg} / \mathrm{min}$ of dopamine. Intermittent mandatory ventilation had been reduced to 4 breaths/min with $40 \%$ inspired oxygen. Nevertheless, the following day the patient again developed insidious low cardiac output. Cardiac tamponade was excluded by resternotomy. Despite reinstitution of all supportive measures she died five days after operation.

At the coroner's postmortem examination, a large thrombus occupied nearly half of the left atrium and extended across the orifice of the xenograft prosthesis. The major coronary arteries were normal on gross examination. Histological examination of the mass removed at operation showed the characteristic features of a papillary tumour or giant Lamdl's excrescence. In retrospect, this could be identified on the preoperative echocardiogram and left ventricular angiogram (Fig. 1). 


\section{Discussion}

Primary cardiac tumours are rare, the commonest being myxomas and papillary tumours of the heart valves. ${ }^{2}$ The latter generally have been incidental findings at postmortem examination or open heart surgery. Because of their predilection for the ventricular surface of the semilunar valves and atrial surface of the atrioventricular valves, as well as their histological similarity to Lamdl's excrescence, the papillary tumour has been thought to originate from mural thrombus. ${ }^{34}$ Nevertheless, the ultrastructure and histochemistry are not unlike that of the atrial myxoma, ${ }^{5}$ and both single and multiple tumours have been found within the left ventricle. ${ }^{467}$

While the aetiology and classification of the papillary tumour and giant Lamdl's excrescence remain controversial, this case and other recent observations indicate they may not be as harmless as previously believed. Prolapse into a sinus of Valsalva has obstructed the right coronary ostium, producing chest pain $^{89}$ and causing sudden death. ${ }^{10}$ Coronary ${ }^{711}$ and cerebral emboli 12 have been associated with such lesions and, in this case, occurred while the patient was in sinus rhythm, suggesting the possibility of a cardiac tumour. ${ }^{13}$

Like many of the reported cases, this left ventricular papillary tumour was found in a patient who had undergone previous valvotomy for rheumatic mitral stenosis. ${ }^{67}$ Whether endocardial injury at the time of valvotomy provides a nidus for mural thrombus and subsequent papillary tumour formation or the rheumatic process is associated with these lesions is unknown. Alternatively, an undetected abnormality of haemostasis may have predisposed to both the formation of the papillary tumour and thrombosis of the mitral valve prosthesis.

While the risk of late degeneration in gluteraldehyde-preserved porcine bioprostheses is recognised, low thrombogenicity has made them an attractive alternative to mechanical devices for cardiac valve replacement. The reported incidence of thromboembolic episodes with the Carpentier-Edwards and other mitral xenograft valves ranges from $0 \%^{1415}$ to about $11 \%$ per patient per year, ${ }^{16}$ depending, in some series, on the patient population and the use of anticoagulation or antiplatelet treatment. Rarely, thrombotic stenosis has developed in xenograft valves implanted for longer than one month. ${ }^{17}$ This was manifest by systemic emboli, ${ }^{18}$ prosthetic occlusion, ${ }^{19}$ or signs of prosthetic valve stenosis. ${ }^{20}$ Such valves had acute or organising thrombus in one or more cusps, thought to be the result of primary thrombogenicity of the valve tissue, ${ }^{17}$ infection, ${ }^{19}$ or impaired cusp mobility from muscle, ${ }^{21}$ degeneration, ${ }^{11}{ }^{19}$ or haematoma. ${ }^{22}$
In contrast to late thrombotic complications, early thrombus formation does not appear to be related to the heterograft tissue. An incidental finding in four of 32 Hancock valves removed within one month of insertion, ${ }^{17}$ the clot was attached to the prosthetic sewing ring or left atrium and in no case obstructed the valve orifice. Factors predisposing to early thrombus formation were postoperative low cardiac output, atrial fibrillation, a Dacron sewing ring in the left atrium, and absence of anticoagulation. ${ }^{172023}$

All of these factors were present in our patient, who developed much more extensive thrombosis than previously observed with a xenograft prosthesis. In addition, the strip of Teflon felt used to reinforce the mitral annulus in the left atrium may have contributed to clot formation, which almost certainly resulted in recurrence of low cardiac output by progressive occlusion of the prosthetic orifice. Had this complication been suspected, it could have been diagnosed by echocardiography and possibly treated by streptokinase infusion or surgical removal. Recognition of such a patient at risk of early valve thrombosis would be a clear indication for anticoagulation in the early postoperative period.

\section{References}

1 Wold LE, Lie JT. Cardiac myxomas. Am $\mathcal{F}$ Pathol 1980; 101: 219-33.

2 Heath D. Pathology of cardiac tumors. Am $\mathcal{f}$ Cardiol 1968; 21: 315-27.

3 Salyer WR, Page DL, Hutchins GM. The development of cardiac myxomas and papillary endocardial lesions from mural thrombus. Am Heart f 1975; 89: 4-17.

4 Pomerance A. Papillary 'tumours' of the heart valves. $\mathcal{F}$ Pathol Bacteriol 1961; 81: 135-40.

5 Stovin PGI, Heath D, Khaliq SU. Ultrastructure of the cardiac myxoma and the papillary tumour of heart valves. Thorax 1973; 28: 273-85.

6 Heath D, Thompson IM. Papillary "tumours" of the left ventricle. Br Heart f 1965; 29: 950-4.

7 Cha SD, Incarvito J, Fernandez J, Chang KS, Maranhao V, Gooch AS. Giant Lamdl's excrescences of papillary muscle and aortic valve; echocardiographic, angiographic and pathologic findings. Clin Cardiol 1981; 4: $51-4$.

8 Heath D, Best PV, Davis BT. Papilliferous tumours of the heart valves. $\mathrm{Br}$ Heart $\mathrm{f}$ 1961; 23: $20-4$.

9 Shub C, Tajik AJ, Seward JB, et al. Cardiac papillary fibroelastomas. Mayo Clin Proc 1981; 56: 629-33.

10 Butterworth JS, Poindexter CA. Papilloma of cusp of the aortic valve. Circulation 1973; 48: 213-5.

11 Harris LS, Adelson L. Fatal coronary embolism from a myxomatous polyp of the aortic valve. Am $\mathcal{F}$ Clin Pathol 1965; 43: 61-4.

12 Ong LS, Nanda NC, Barold SS. Two-dimensional 
echocardiographic detection and diagnostic features of left ventricular papillary fibroelastoma. Am Heart $\mathcal{F}$ 1982; 103: 917-20.

13 St John Sutton MG, Mercier LA, Giuliani ER, Lie JT. Atrial myxomas. Mayo Clin Proc 1980; 55: 371-6.

14 Nuñez L, Aguado MG, Larrea JL, Celemin D, Oliver J. Prevention of thromboembolism using aspirin after mitral valve replacement with porcine bioprosthesis. Ann Thorac Surg 1984; 37: 84-7.

15 Geha AS, Hammond GL, Laks H, Stansel HC, Glenn WWL. Factors affecting performance and thromboembolism after porcine xenograft cardiac valve replacement. f Thorac Cardiovasc Surg 1982; 83: 377-84.

16 Jamieson MPG, Bennett JG, Robles A, Ross DN. Clinical experience with the Carpentier-Edwards porcine xenograft. Thorac Cardiovasc Surg 1981; 29: 200-5.

17 Thiene G, Bortolotti U, Panizzon G, Milano A, Gallucci V. Pathological substances of thrombus formation after heart valve replacement with the Hancock bioprosthesis. f Thorac Cardiovasc Surg 1980; 80: 414-23.
18 Bennett EV Jr, Grover FL, Trinkle JK. Porcine valve bioprosthesis; early thrombosis and systemic emboli. Ann Thorac Surg 1982; 33: 197-9.

19 Platt MR, Mills LJ, Estrera AS, Hillis LD, Buja LM, Willerson JT. Marked thrombosis and calcification of porcine heterograft valves. Circulation 1980; 62: 862-9.

20 Sands MJ, Lachman AS, Leach CN Jr, Takata H, McLucas E. Thrombosis of the porcine heterograft heart valve prosthesis. Conn Med 1981; 45: 7-11.

21 McComb RD, Stahman FD, O'Connor WN, Todd EP. Structure-related thrombosis involving a porcine xenograft valve. Ann Thorac Surg 1979; 27: 191-3.

22 Ishihara T, Ferrans VJ, Barnhart GR, Jones M, McIntosh CL, Roberts WC. Intracuspal hematomas in implanted porcine valvular bioprostheses. F Thorac Cardiovasc Surg 1982; 83: 399-407.

23 Hetzer R, Hill JD, Kerth WJ, Wilson AJ, Adappa MG, Gerbode F. Thrombosis and degeneration of Hancock valves: clinical and pathological findings. Ann Thorac Surg 1978; 26: 317-22. 